\title{
DESIGNING AND FABRICATION OF A LOW-COST DIP-COATER FOR RAPID PRODUCTION OF UNIFORM THIN FILMS
}

\author{
David A. Castillo-Vilcatoma ${ }^{a}$, Steveen J. Loarte ${ }^{\mathrm{a}}$, Arturo A. Fernandez-Chillcce ${ }^{\mathrm{a}}$, Elizabeth C. Pastrana ${ }^{\mathrm{b}, *,(\mathcal{C})}$ and Roxana \\ Y. Pastrana ${ }^{a}$ \\ aBiomet Research Group, Universidad Nacional de Ingeniería, P.O. Box 31-139, Av. Túpac Amaru 210, Lima, Perú \\ ${ }^{b}$ Center for the Development of Advanced Materials and Nanotechnology, Universidad Nacional de Ingeniería, P.O. Box 31-139, \\ Av. Túpac Amaru 210, Lima, Perú
}

Recebido em 27/04/2021; aceito em 16/07/2021; publicado na web em 10/08/2021

\begin{abstract}
In this work, a self-made dip-coater equipment was developed for the fabrication of thin films. The assembly of the apparatus was carried out using simple mechanical and electronic pieces, recycle parts, and spending an inexpensive budget suitably. The production, software design, and features of the device were focused on the sol-gel dip-coating method, which involves gravitational draining and drying processes, as well as continued condensation reactions. The dip-coater was based on the Arduino microcontroller and a step motor. The immersion speed in the solution, the waiting time, and the withdrawal process were typed by a digital control panel, where the optimal range found for speed was $0.1-6.0 \mathrm{~mm} \mathrm{~s}^{-1}$ without vibration interferences. The total fabrication cost of the fabricated dip coater was less than 100 USD and the assembly process was not complicated. Finally, the performance of the dip-coater was evaluated through the deposit of copper oxide and iron oxide films on fluorine-doped tin oxide glass substrates layer by layer. The field emission scanning electron microscopy cross-section images confirm the formation of thin films with thickness in the nanoscale range, with good stability and sameness achieved through the control thickness during the dip-coating method under ambient conditions.
\end{abstract}

Keywords: laboratory equipment; computer-based learning; nanotechnology; materials science.

\section{INTRODUCTION}

The dip-coater is coating equipment that uses the liquid deposition technique employed in research and industrial production of hybrid, inorganic, and polymeric thin films with controlled thickness. ${ }^{1} \mathrm{~A}$ thin film can be explained as a layer of material, where the thickness ranges from fractions of a nanometer to few micrometers. ${ }^{2}$ The thin films fabricated by the dip-coating technique are used in many fields of application such as electronics, optics, photocatalysis, among others. ${ }^{3}$ This technique involves complex chemical and physical variable parameters. The coated, as well as the thickness and morphology of films, were governed by various parameters such as immersion time, withdrawal speed, cycles of recovering, density, viscosity, surface tension, substrate surface, and evaporation conditions of precursors solutions. ${ }^{4}$ Notwithstanding the many factors associated with the determination of the magnitude of the forces and how the equilibrium between them is reached, almost all of them are constant for a given specific solution. In the coating process, the thickness (h) of the films formed during dip coating is most closely given according to the Landau-Levich (Equation (1)), where $\mathrm{c}$ is a constant (0.944) dependent on the behavior of a solution, $\rho$ is the density of the solution, $\gamma$ is the surface tension at the liquid-air interface, and $\eta$ is the viscosity of the solution. The value $g$ is the gravitational constant and $U$ is the withdrawal speed. ${ }^{5,6}$

$$
\mathrm{h}=\mathrm{c} \frac{(\eta U)^{2 / 3}}{\gamma^{1 / 6}(\rho g)^{1 / 2}}
$$

Dip-coaters are the most used instruments for the fabrication of thin films in many laboratories, providing homogeneous and smooth films. Indeed, a dip coater is useful to deposit thin films with desired features related to film thickness, homogeneity, and reproducibility. ${ }^{7}$ Therefore, this equipment becomes important as the key to the production of high-quality thin films easily. At present, the classical dip coaters for research are commercially affordable although rather expensive (typically between 2000 - 4000 USD). Besides, the budget reported cost by other laboratories for the fabrication of a homemade dip coater was not less than 250 USD. ${ }^{8}$ Likewise, an additional expense is required for their maintenance or repair, which limits their use in no specialized laboratories.

Recently, special attention has been focused on the use of microcontroller boards such as Arduino for the fabrication of low-cost laboratory equipment. ${ }^{9}$ Arduino is one of the most popular opensource computing hardware platforms with permissive licenses that can be freely redistributed and modified by anyone, usually a low cost to scientific instrumentation. ${ }^{10-12}$ Arduino permits more easily programming and manipulation than other equipment. ${ }^{13}$

Based on the above considerations, the present paper mainly focused on a low-cost and portable dip-coater fabricated using the Arduino as a microcontroller and a recycled step motor from a printer. The assemble dip coater worked with immersion and withdrawal speed in the range of $0.1-6.0 \mathrm{~mm} \mathrm{~s}^{-1}$ with a power supply of $12 \mathrm{~V}$. The system can be set, through portable electronic devices, independently for two modes of operation: manual and automatic. The fact of not using a computer it makes be more accessible and practical than other dip-coater reported..$^{14,15}$

In order to confirm our self-build device performance and that its use in this research produces thin films (h in nanometers), copper oxide $(\mathrm{CuO})$ and iron oxide $\left(\alpha-\mathrm{Fe}_{2} \mathrm{O}_{3}\right)$ films were fabricated onto fluorine-doped tin oxide glass (FTO) substrates, obtaining highquality thin films. Finally, the accurate description and construction of dip-coater equipment for less than 100 USD was reported.

*e-mail: epastrana@uni.edu.pe 


\section{MATERIALS AND METHODS}

\section{Electrical and electronic components}

The general construction of a dip-coater is presented in Figure 1. Specifically, in our work, the dip-coater was moved by using an electrical part composed of an inexpensive recycled stepper motor (Epson printer; model LQ-2090) controlled by the electronic part conformed by an Arduino microcontroller (SparkFun Electronics, Mega 2560) and an EasyDriver (Sparkfun, model SX09402). The software used was Arduino IDE 1.8.13. Besides, the other electrical parts used were a Liquid Crystal Display, LCD (Hitachi HD44780 20x4), a regulated Switching Power Supply (Joolonpor, S-60-12 DC 12V 5A), a PCB universal board, some electrical wires, switches, and buttons. Details concerning the materials cost as well as teaching recommendations are presented in the Supplementary Material.

In order to control the maximum height of the path available for the arrangement composed of the wooden support and the standard crocodile clips, a Micro limit switch SPDT (DaierTek, model KW3-0Z) connected to the Arduino was used. When the dip-coater is turned on, the crocodile clips disposition is positioned at the top of the lead screw allowed, labeled as the home position. After that, the user can enter the parameters desired. Figure 1 shows the frontal and inside view of the dip-coater switched on using the electrical and electronic parts described above. Except for the wires, the other parts of the figure were attached through glue on the solid pine wooden frame.

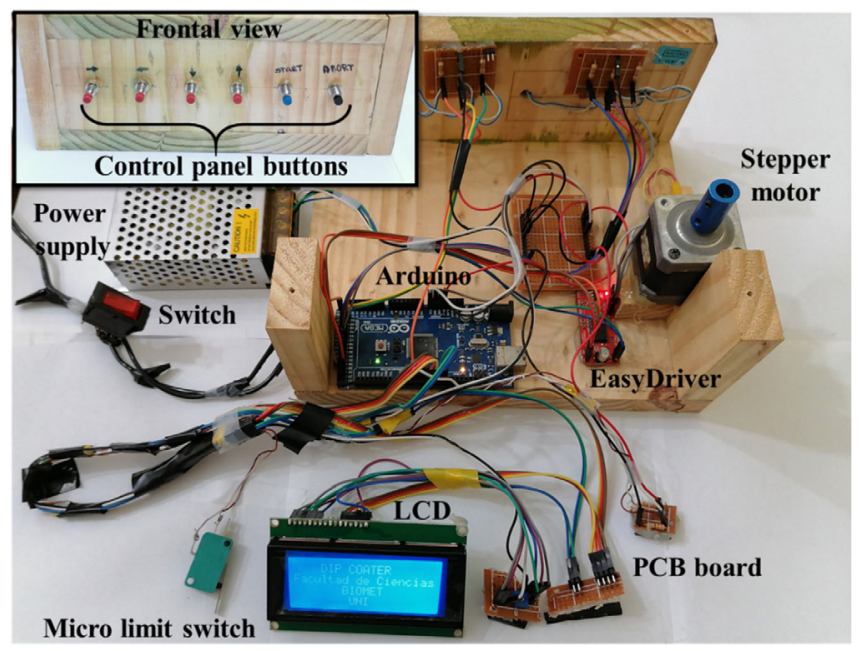

Figure 1. Wiring of the Arduino-based dip coater. The control panel buttons in the frontal view of the dip-coater are shown as an inset

Arduino microcontroller has a role as a signal trigger, which is used for control of the speed and direction of rotation to step motor with a high degree of accuracy. The rotor of a stepper, seated on a series of magnets, is controlled by a series of coils that are charged positively and negatively in sequence, moving it forward or backward in discrete "steps", one step at a time. The motor moves 1.8 degrees per step, this equals 200 steps for a 360 degrees rotation. On the other hand, the EasyDriver employed a current supply and handled the current regulation required to the step motor to avoid its damage. Based on the rotation of the motor and the input time of the step assigned, the dipping speed can be calculated as follows:

$$
\text { Speed }(\mathrm{mm} / \mathrm{s})=3 \times\left[\frac{\mathrm{n} \times 2 \pi}{\mathrm{N}_{\text {step }} \times \mathrm{t}_{\text {step }}(\mathrm{s})}\right]
$$

where speed is expressed in millimeters per second, $\mathrm{n}$ is the number of revolutions of step motor, $\mathrm{N}_{\text {step }}$ is the number of steps for revolution, $t_{\text {step }}$ is the time between steps, and finally, the number 3 corresponds to the radius of the motor shaft in millimeters. The minimum speed measured for the stepper motor was $0.1 \mathrm{~mm} \mathrm{~s}^{-1}$, whereas, the maximum speed measured was $6.0 \mathrm{~mm} \mathrm{~s}^{-1}$ without any vibration of the parts, particularly of the threaded rod, which could disturb the deposition by immersion of the film and the subsequent withdrawal of the substrate from the solution.

\section{Mechanical components}

The mechanical part of the dip-coater involves the equipment body that encloses the rest of the device's components. Each part of the dip-coater body in a real proportion model was drawn and the complete simulation assembly test was developed by using Solidworks 2018 program. Figures $2 \mathrm{a}$ and $2 \mathrm{~b}$ show images of the dip-coater pieces designed employing Solidworks and the image of the dip-coater already fabricated, respectively. It could be mentioned that two substrates, each placed on the different crocodile clips, can be coated using the dip-coater machine at the same time and with the same settled parameters.

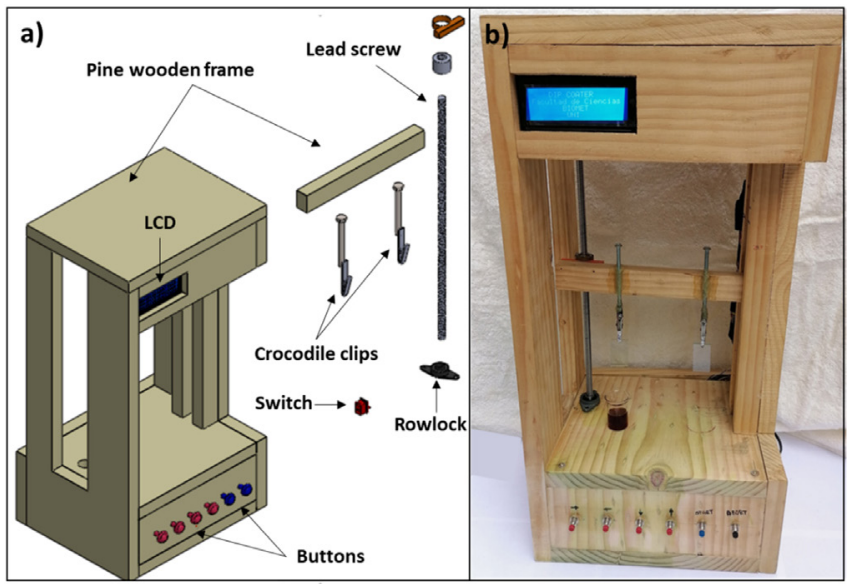

Figure 2. a) $3 D$ schematic design and, b) Dip-coater fabricated from the printer step motor

\section{Code}

To set the parameters desired of the dip-coater built, an Arduino code was elaborated. The user could enter the values of dip speed, dip duration, dip length, dry duration, and the number of dips, which are displayed on the LCD. After that, the code receives the orders and computes them, adjusting the angle of rotation and waiting for the time until the stepper motor starts again. The Arduino code is available in the Supplementary Material.

\section{TESTING THE DIP-COATER}

\section{Performance experiment}

In order to determine the system performance, different thin films of copper oxide $(\mathrm{CuO})$ and iron oxide $\left(\alpha-\mathrm{Fe}_{2} \mathrm{O}_{3}\right)$ were fabricated using precursor solutions prepared by the sol-gel method according to Pastrana et al. ${ }^{16}$ The films were deposited onto FTO glass conductive plates (Dyesol company, $7 \Omega \mathrm{cm}^{-2}, 2.2 \mathrm{~mm}$ thickness) of $3.5 \mathrm{~cm} \mathrm{x} 2 \mathrm{~cm}$ of area. The dip-coating parameters were optimized after running a series of experiments. The FTO substrates were dip length $7 \mathrm{~cm}$ into the different precursor solutions with a constant entrance speed of 
$2 \mathrm{~mm} \mathrm{~s}^{-1}$ and remained in these solutions for 15 seconds before pulling out. Then, the substrate was withdrawn from the sol with $2 \mathrm{~mm} \mathrm{~s}^{-1}$ of speed and was dried using an infrared light source for $3 \mathrm{~min}$ at room temperature. Finally, the samples deposited onto the substrate were heat treatment at $500{ }^{\circ} \mathrm{C}$ and $600{ }^{\circ} \mathrm{C}$ for $\mathrm{CuO}$ and $\alpha-\mathrm{Fe}_{2} \mathrm{O}_{3}$, respectively. The time for calcined was $1 \mathrm{~h}$ with a heating rate of $10{ }^{\circ} \mathrm{C} \mathrm{min}{ }^{-1}$. This procedure was repeated for $\mathrm{CuO}$ and $\alpha-\mathrm{Fe}_{2} \mathrm{O}_{3}$ fifty and five times, respectively. It should be noted that the crocodile clips are fixed in the pine wooden frame, which in turn is attached to the lead screw moving just up and down. Therefore, only manual change of each beaker containing the precursor solutions of each oxide is required. A diagram of the procedure carried out and the final thin film oxides obtained are shown in Figures $3 a$ and $3 b$, respectively.

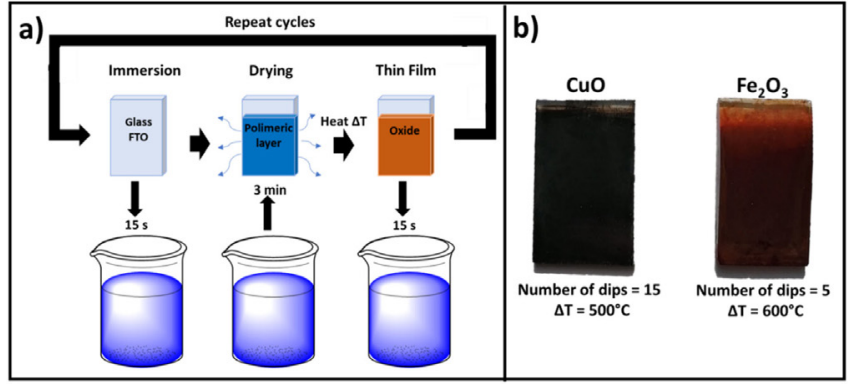

Figure 3. a) Schematic procedure diagram for oxides thin films fabrication and b) thin films oxides fabricated after the dip-coating technique

The film morphologies and cross-sections were investigated by Hitachi SU-8230 field emission scanning electron microscope (FE-SEM) equipped with an energy dispersive $\mathrm{X}$-ray spectrometer (EDX). FE-SEM images of $\mathrm{CuO}$ and $\alpha-\mathrm{Fe}_{2} \mathrm{O}_{3}$ thin films are shown in Figures $4 \mathrm{a}$ and $4 \mathrm{c}$, respectively. As shown, the average size of quasi-spherical $\mathrm{CuO}$ crystals is $53 \pm 8 \mathrm{~nm}$ (Figure 4a). In the case of $\alpha-\mathrm{Fe}_{2} \mathrm{O}_{3}$, a worm-like morphology was obtained, ${ }^{11}$ with an estimated diameter of $63 \pm 10 \mathrm{~nm}$ (Figure $4 \mathrm{c}$ ), both morphologies were usually reported in previous research. ${ }^{17-19}$

Figures $4 \mathrm{~b}$ and $4 \mathrm{~d}$ display cross-sectional FE-SEM images of $\mathrm{CuO}$ and $\alpha-\mathrm{Fe}_{2} \mathrm{O}_{3}$ films, respectively. The thickness values obtained were approximately $802 \mathrm{~nm}$ and $376 \mathrm{~nm}$ for $\mathrm{CuO}$ and $\alpha-\mathrm{Fe}_{2} \mathrm{O}_{3}$, respectively. Furthermore, the EDX analysis shown in Figures $4 \mathrm{~b}$ and $4 \mathrm{~d}$ confirms the presence of copper and iron metal, respectively, without diffusion of atoms. The results obtained confirm the formation of two-dimensional nanometric material willing as a thin film.

The morphologies of the films with spherical and wormshaped obtained for $\mathrm{CuO}$ and $\alpha-\mathrm{Fe}_{2} \mathrm{O}_{3}$ films, respectively, were in
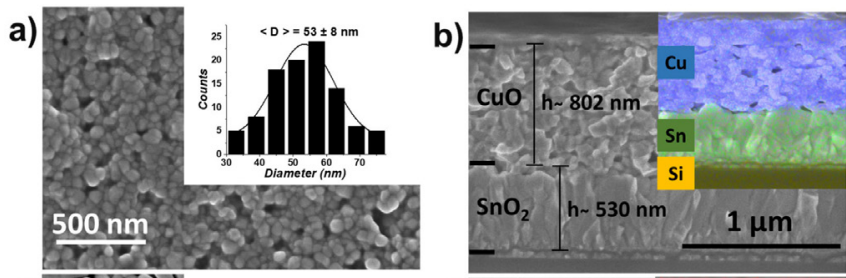

c)
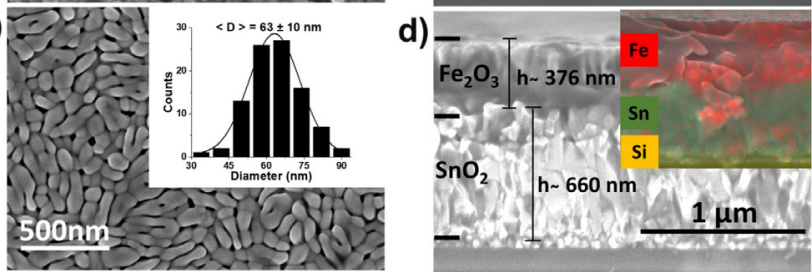

Figure 4. FE-SEM top-view and cross-sectional images of $\mathrm{CuO}(a, b)$ and $\alpha-\mathrm{Fe}_{2} \mathrm{O}_{3}(\mathrm{c}, d)$ films fabricated by dip-coating technique. The size distributions and corresponding standard deviations are shown as insets agreement with results obtained by dip-coating in previous works. ${ }^{20,21}$ Furthermore, coating attained for $\mathrm{CuO}$ and $\alpha-\mathrm{Fe}_{2} \mathrm{O}_{3}$ using the dipcoater fabricated in our research could be compared with other physical accuracy techniques of fabrication. ${ }^{22-24}$

\section{HAZARDS}

The circuits of the dip-coater use a low voltage (12 V, $0.5 \mathrm{~A})$, thus no electrical shock risk exists. Notwithstanding, electrical safety measures have been taken as using electrical tape to insulate all wires and electrical pieces. Besides, because the wooden pine frame and other equipment components are burnable, they should be handled with care and kept away from heat, hot surfaces, sparks, open flames, and other ignition sources. The dip-coater should be seated on a firm, not sloped surface. We recommend fixing the beaker, that contains the precursor solution, to the device to avoid spills. Finally, it would be appropriate to wear personal protective equipment for handling it.

\section{CONCLUSIONS}

A low-cost dip-coater Arduino-based was fabricated from a step motor recycled of a printer and other no expensive components. The total fabrication cost of this equipment was less than 100 USD. The speed of the dip-coater was set in the range of $0.1-6.0 \mathrm{~mm} \mathrm{~s}^{-1}$ left out vibrations and controlled by the motor driver. The user can get started straight away once entering the parameters desires, either just one cycle coating or multiple coating cycles. Measurement results obtained in this research work are repeatable and consistent with the results achieved by previous works. The dip-coater was tested in the fabrication of $\mathrm{CuO}$ and $\alpha-\mathrm{Fe}_{2} \mathrm{O}_{3}$ thin films, demonstrating a high quality of these films in terms of crystallinity and homogeneity, as well as in obtaining their thicknesses in the nanometric range. It could be mentioned that this equipment can be constructed by students, the operation is familiar and simple for untrained personnel. The goals achieved were the simple and economic fabrication of dip-coaters, likewise an improvement in the construction behavior of simple devices based on computer programming.

\section{SUPPLEMENTARY MATERIAL}

Materials list, wiring circuit, assembling of electrical and mechanical parts, and Arduino code are described at the supplementary material and free of charge at http://quimicanova.sbq.org.br.

\section{ACKNOWLEDGMENTS}

The authors thank Dr. Pierre Ramos Apestegui of the Center for the Development of Advanced Materials and Nanotechnology at the National University of Engineering for his excellent support and advice for the article. Also, the authors thank Dr. Hugo Alarcón Cavero of Gisma Lab at the National University of Engineering for his important guidance in the synthesis of thin films. Finally, the authors thank Dr. Eric Tavares da Costa of LAIA at São Paulo University for his advice on the electronic part of this article.

\section{REFERENCES}

1. Catauro, M.; Papale, F.; Piccirillo, G.; Bollino, F.; Polym. Eng. Sci. 2017, $57,478$.

2. Jilani, A.; Abdel-wahab M. S.; Hammad A. H. In Modern Technologies for Creating the Thin-film Systems and Coatings; Nikitenkov, N. N., ed.; Intech: Croatia, 2017, ch. 8. 
3. Kumar, K. D. A.; Ganesh, V.; Shkir, M.; AlFaify, S.; Valanarasu, S.; J. Mater. Sci: Mater. Electron. 2018, 29, 887.

4. Dey, M.; Doumenc, F.; Guerrier, B.; Eur. Phys. J. E: Soft Matter Biol. Phys. 2016, 39, 19.

5. Brinker, C. J. In Chemical Solution Deposition of Functional Oxide Thin Films; Schneller, T.; Waser, R.; Kosec, M.; Payne, D.; eds.; Springer: Germany, 2013, ch. 10.

6. Ahn, K.; Kim, D.; Kim, O.; Nam, J.; J. Coat. Technol. Res. 2015, 12, 855 .

7. Bindini, E.; Naudin, G.; Faustini, M.; Grosso, D.; Boissière, C.; J. Phys. Chem. C 2017, 121, 14572.

8. Dabirian, R.; Guerrero, V. H.; Loza, D.; Momento 2014, 49, 13.

9. Sadegh-cheri, M.; J. Chem. Educ. 2020, 97, 2338.

10. Kim, S. M.; Choi, Y.; Suh, J.; Appl. Sci. 2020, 10, 5018.

11. Zhang, Q.; Brode, L.; Cao, T.; Thompson, J. E.; J. Chem. Educ. 2017, 94, 1562.

12. Enciso, P.; Luzuriaga, L.; Botasini, S.; J. Chem. Educ. 2018, 95, 1173.

13. Machuno, L. G. B.; Oliveira, A. R.; Furlan, R. H.; Lima, A. B.; Morais, L. C.; Gelamo, R. V.; Mater. Res. 2015, 18, 775.

14. Oliveira, A. R. M.; Zarbin, A. J. G.; Quim. Nova 2005, 28, 141.
15. Adámek, P.; Edukacja, Technika, Informatyka 2016, 7, 152.

16. Pastrana, E. C.; Zamora, V.; Wang, D.; Alarcón H.; Adv. Nat. Sci: Nanosci. Nanotechnol. 2019, 10, 035012.

17. Tran, T. H.; Nguyen, V. T.; Int. Schol. Res. Not. (2014), doi: $10.1155 / 2014 / 856592$.

18. Ashraf, M.; Khan, I.; Usman, M.; Khan, A.; Shah, S. S.; Khan, A. Z.; Saeed, K.; Ehsan, M. F.; Nawaz Tahir, M.; Ullah, N.; Chem. Res. Toxicol. 2020, 33, 1292.

19. Pastrana, E. C.; Loarte, S. J.; Gonzales-Lorenzo, C. D.; Alta R. Y. P.; Alarcón, H. A.; Thin Solid Films 2021, 717, 138440.

20. Shariffudin, S. S.; Khalid, S. S.; Sahat, N. M.; Sarah, M. S. P.; Hashim, H.; IOP Conf. Ser: Mater. Sci. Eng. 2015, 99, 012007.

21. Krysa, J.; Zlamal, M.; Kment, S.; Brunclikova, M.; Hubicka, Z.; Molecules 2015, 20, 1046.

22. Rahman, G.; Joo, O.-S.; J. Mater. Chem. A 2013, 1, 5554.

23. Dolai, S.; Dey, R.; Das, S.; Hussain, S.; Bhar, R.; Pal, A. K.; J. Alloys Compd. 2017, 724, 456.

24. Faiz, H.; Siraj, K.; Khan, M. F.; Irshad, M.; Majeed, S.; Rafique, M. S.; Naseem, S.; J. Mater. Sci.: Mater. Electron. 2016, 27, 8197. 